This item was submitted to Loughborough's Research Repository by the author.

Items in Figshare are protected by copyright, with all rights reserved, unless otherwise indicated.

\title{
Design strategies and preliminary prototype for a low-cost arsenic removal system for rural Bangladesh
}

PLEASE CITE THE PUBLISHED VERSION

PUBLISHER

(C) WEDC, Loughborough University

\section{VERSION}

VoR (Version of Record)

\section{PUBLISHER STATEMENT}

This work is made available according to the conditions of the Creative Commons Attribution-NonCommercialNoDerivatives 4.0 International (CC BY-NC-ND 4.0) licence. Full details of this licence are available at: https://creativecommons.org/licenses/by-nc-nd/4.0/

\section{LICENCE}

CC BY-NC-ND 4.0

\section{REPOSITORY RECORD}

Mathieu, Johanna, Ashok Gadgil, K. Kowolik, S. Qazi, and A.M. Agogino. 2019. "Design Strategies and Preliminary Prototype for a Low-cost Arsenic Removal System for Rural Bangladesh". figshare. https://hdl.handle.net/2134/29840. 


\title{
Design strategies and preliminary prototype for a low-cost arsenic removal system for rural Bangladesh
}

\author{
J.L. Mathieu, A.J. Gadgil, K. Kowolik, S. Qazi \& A.M. Agogino, USA
}

REFEREED PAPER 101

\begin{abstract}
Researchers have invented a material called ARUBA - Arsenic Removal Using Bottom Ash - that effectively and affordably removes arsenic from Bangladesh groundwater. Through analysis of studies across a range of disciplines, observations, and informal interviews conducted over three trips to Bangladesh, we have applied mechanical engineering design methodology to develop eight key design strategies, which were used in the development of a low-cost, community-scale water treatment system that uses ARUBA to remove arsenic from drinking water. We have constructed, tested, and analysed a scale version of the system. Experiments have shown that the system is capable of reducing high levels of arsenic (nearly $600 \mathrm{ppb}$ ) to below the Bangladesh standard of $50 \mathrm{ppb}$, while remaining affordable to people living on less than US\$2/day. The system could be sustainably implemented as a public-private partnership in rural Bangladesh.
\end{abstract}

\section{Introduction}

Naturally occurring arsenic in drinking water is threatening the well-being of more than a hundred million people on six continents. In Bangladesh alone, 28 to 77 million people drink arsenic-laden water from shallow tubewells, the majority of which were installed within the past forty years as an alternative to drinking biologically contaminated surface waters (Ahmad et al. 2003). High levels of arsenic were first noted in the groundwater in the early 1990s. The country is experiencing the largest case of mass poisoning in human history (Smith et al. 2000).

The effects of arsenicosis can take ten to twenty years to appear. Initially arsenic poisoning is painfullesions on the hands and feet make daily chores difficult or impossible. Long-term chronic exposure leads to a variety of very serious health problems, notably diabetes mellitus and cancer of the skin, bladder, kidney, and lung (Chen and Ahsan 2004; Chowdhury 2004). Vascular problems caused by arsenic poisoning can also lead to gangrene and amputations. People with poor nutrition, and hence from a poorer strata of society, are more likely to show signs of arsenicosis (Biswas et al. 1998; Smith et al. 2000).

Researchers at Lawrence Berkeley National Laboratory (LBNL), Berkeley, CA, USA have developed a material called "ARUBA" - Arsenic Removal Using Bottom Ash - that inexpensively removes arsenic from drinking water (Gadgil et al. 2008; Patel et al. 2006). ARUBA uses bottom ash as a substrate. Bottom ash is a finely powdered, sterile waste material from coal-fired power plants, which are common in India. Particles of bottom ash (Photograph 1) are coated with iron (hydr)oxides (Photograph 2), using two inexpensive chemicals $\left(\mathrm{FeSO}_{4}\right.$ and $\left.\mathrm{NaOH}\right)$. The manufacturing process is conducted at room temperature and atmospheric pressure, and thus ARUBA can be produced with simple equipment and at low cost.

Removing arsenic from contaminated drinking water does not require local handling of corrosive or toxic chemicals, or complex engineering operations. ARUBA is mixed into contaminated water, where it reacts with and immobilizes arsenic by adsorption and/or co-precipitation. The resulting arsenic-iron complex is settled out of the water, and is safe enough for disposal in municipal landfills per US EPA standards. Importantly, because of ARUBA's large surface to volume ratio, only a small amount of media is needed to remove a given amount of arsenic. Therefore, ARUBA arsenic removal produces less waste than most comparable technologies. 


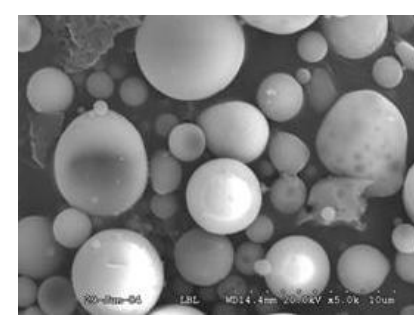

Photograph 1. Scanning electron micrograph of uncoated bottom ash (diameters 1-10 $\mu \mathrm{m}$ ), magnified 5,000x

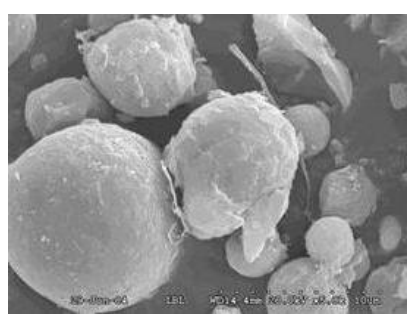

Photograph 2. Scanning electron micrograph of ARUBA (bottom ash coated with iron (hydr)oxides), magnified 5,000x

Laboratory-based tests at LBNL have shown that ARUBA is able to lower arsenic concentrations in spiked deionised water from $2000 \mathrm{ppb}$ to below the World Health Organization (WHO) standard of $10 \mathrm{ppb}$ (Gadgil et al. 2008; Patel et al. 2006). Field results have proven that ARUBA is effective at reducing high levels of arsenic (up to $880 \mathrm{ppb}$ ) in Bangladesh groundwater to below the Bangladesh standard of $50 \mathrm{ppb}$ in twelve tubewells located in four upazilas (sub-districts) of the country (Gadgil et al. 2008; Mathieu et al. 2008). Adding higher concentrations of ARUBA can achieve arsenic concentrations below the WHO standard (Gadgil et al. 2008).

This paper presents the design of a low-cost, community-scale water treatment system that uses ARUBA to remove arsenic from groundwater. Using mechanical engineering design methodology, we have developed a list of eight design strategies based on literature, field observations, and informal interviews with villagers. We begin by discussing these strategies and how they have defined our design. We then present the design and analysis of a small-scale prototype water treatment system (10-litre per hour) that was constructed and tested in Bangladesh in Summer 2008, and a 100-litre per hour prototype system that is currently undergoing testing in Bangladesh. We detail our cost analysis and discuss a possible implementation model that could provide sustainable water treatment services to rural Bangladeshis. We conclude with lessons learned.

\section{Design strategies}

Much of the research on arsenic removal technologies for Bangladesh has focused only on technical solutions. Analysis of user preferences and costs appear as footnotes to technical designs and testing. Plans for implementation, scalability, and sustainability are often left out completely. However, several socioeconomic, health, and interdisciplinary arsenic studies conducted in Bangladesh over the past ten years have gathered data on user preferences. Over the past several decades the field of mechanical engineering has developed and formalized design methodology in which user preferences are integrated into the engineering design process. We can apply this same methodology to water engineering problems. Importantly, this allows us to develop more acceptable and sustainable water treatment systems.

We have identified eight design strategies (a summary is presented on the following page) through analysis of existing studies, in addition to field observations and informal interviews with Bangladeshi villagers during three trips to Bangladesh in 2007 and 2008. Also, during the summer of 2008, our group deployed a $600+$ household study on perceptions of arsenic and arsenic-removal technologies. Data is still being processed and will be published in a future document. We expect this information will help us refine our design strategies in the coming year.

Our first design strategy is to maximize the effectiveness of the technology. In our prior work, we have detailed ARUBA's effectiveness in removing arsenic from contaminated Bangladesh groundwater (Mathieu et al. 2008; Gadgil et al. 2008).

Our second design strategy addresses the appropriate scale of the technology. Many technical studies have proposed household-based filters; however, in an extensive study for the World Bank, Ahmad et al. (2003) found that $72 \%$ of villagers surveyed would choose a community-based technology over a household filter. This may result from other preferences held by villagers. For instance, several studies have found that villagers listed convenience as the most important attribute of a water treatment system (Ahmad et al. 2003; Caldwell et al. 2003). Community-scale systems, especially those maintained by a trained technician, are more convenient than household filters in terms of individual time spent using and maintaining the system. 
Several studies report household filters being abandoned because they required too much attention and maintenance (Ahmad et al. 2003; Hoque et al. 2004). Therefore, we have incorporated ARUBA into the design a community-scale treatment centre to minimize perceived inconvenience (strategy 2 ).

\section{Summary of key design strategies}

- Maximize effectiveness of arsenic removal technology

- Design community-scale treatment centre to minimize perceived inconvenience

- Minimize distance between homes and water treatment centre, or provide water delivery

- Enhance perception of treated water quality

- Build trust in technology through continuous water monitoring and guaranteeing technical efficacy

- Minimize cost to villagers

- Allow for ease of local water management (source monitoring)

- Ensure feasibility of arsenic removal waste management

In some villages arsenic-free deep aquifers have been found below arsenic-contaminated shallow aquifers and so a common solution has been to install a deep tubewell to pump arsenic free water to the surface. Unfortunately, it is substantially more expensive to drill a deep tubewell than a shallow one. Because of the cost many families, or even whole villages (up to 2000 people), are forced to share one deep tubewell. In addition, this cannot provide an overall solution to the arsenic problem in Bangladesh because arsenic-free deep aquifers are not accessible in all villages. Furthermore, over time, deep aquifers reportedly become contaminated with arsenic as water from contaminated shallow aquifers infiltrates the deep reservoirs. However, we can learn from several studies that have analyzed villagers' perceptions of deep tubewells.

Villagers have reported a preference for fetching water from deep tubewells over using and maintaining a household-based filter to remove arsenic, but their most common complaint is the distance to the deep tubewell (Ahmad et al. 2003). Most villagers have shallow (and inexpensive) tubewells in their yard. In several villages in Jessore District, we spoke with villagers who had to walk $200-500 \mathrm{~m}$ to fetch water from community-owned deep tubewells. These distances were considered far. While people reported that they generally fetched drinking water from the deep tubewell, most also admitted that they would drink water out of contaminated tubewells when they did not want to make the trip to the arsenic-free source. In North Nolua (Matlab District), where families were not using a community source, men reported that it would put women and their children in danger if the women had to walk far from their family's compound to collect water. Caldwell et al. (2003) state that both fetching water from outside family compounds and maintaining a household water treatment unit, "reverses the process of relieving Bangladeshi women of some of their onerous workload." Therefore, minimizing the distance to safe water sources and/or providing water delivery (strategy 3 ) is important for the success of a community water treatment centre.

In designing an arsenic removal unit, it is necessary to ensure that villagers have a positive perception of the treated water's quality (strategy 4). In North Nolua, all of the villagers we spoke to associated water quality with the look and taste of the water. In Bangladesh, water often contains high levels of iron, which precipitates out of solution and tinges the water yellow-orange when it is stored. We tested two tubewells approximately ten metres apart and found that villagers chose to drink out of the tubewell containing more than $400 \mathrm{ppb}$ arsenic because the water looked cleaner and tasted better than the other tubewell containing 2 ppb arsenic and high levels of iron. Hoque et al. (2004) found that villagers complained about poor water quality from household filters. A water treatment system will not succeed if the treated water is perceived to be of a quality lower than that of the source.

Villagers must trust that the water treatment system is working to remove arsenic, and not introducing biological or other chemical contaminants (strategy 5). Chemical packets that remove arsenic from drinking water have not succeeded in Bangladesh because villagers could not tell if they were working, and were sceptical of a technology that was not explained to them (Hoque et al. 2000). Effective implementation of a community-scale system must include community education about the devastating effects of arsenic and the method of arsenic removal, and must build a level of trust in the technology. Importantly, with communityscale treatment, water quality is easy to monitor. Thus, it is possible to issue guarantees that the technology is working to remove arsenic. At the household-scale users would not generally get this feedback.

For an arsenic removal technology to succeed, treatment costs must be minimized (strategy 6). In Jafornagar, we visited a community-scale arsenic-treatment unit that had been donated to a village. 
Unfortunately, villagers explained that they were unable to afford the annual filter cartridge replacement cost, reported to be US\$60-\$75, so the treatment unit had sat unused for more than three years. Similarly, many household filters (e.g., the SONO filter described in Hussam and Munir (2007)) have only been adopted with significant subsidies or donations because of large initial costs: US\$40-\$50 for a filter with a lifetime of five years, a huge sum of money for risk-averse villagers living on less than US\$2 per day and generally exhibiting very high discount rates. Moreover, it is difficult for villagers to secure microfinance loans for household-based water treatment when such systems have little to no possibility of income generation. A community-scale system operating with a pay-as-you-go model does not require individual villagers to make large capital investments, instead villagers can purchase the amount of treated water that they need on a day-to-day basis. The system requires the village council, or some other entity to finance the project. Fortunately, it is much easier for a village council to take out a loan.

Several design strategies were developed through consideration of factors other than user needs. From a policy standpoint, water treatment systems should allow for ease in local water management (strategy 7), and, if possible, increase the effectiveness of local and national water policies. Fortunately, this is simpler with community-scale treatment since water quality can be monitored and guaranteed, something that has been lacking in the ad-hoc development of rural clean water systems in Bangladesh (Ahmad et al. 2003).

An important logistical consideration is that all arsenic removal systems produce waste. Despite the fact that spent ARUBA is US EPA approved for disposal in a US municipal landfill, on our most recent trip to Bangladesh we learned that Bangladesh policies require spent arsenic removal media to be buried in concrete pits lined with thick plastic-membranes located far away from human habitation. Fortunately, treating water in central locations simplifies waste management. A water treatment system should maximize the feasibility of waste management (strategy 8). Again, community-scale technologies make this possible. The same vehicle that delivers ARUBA to a community treatment centre could also take the spent media away for burial or reprocessing, if the latter proves affordable.

\section{Prototype design, testing, and analysis}

To fulfil the design strategies presented above we propose the design of a community-scale water treatment system implemented as a public-private partnership in rural Bangladeshi villages. This decision directly addresses strategy 2, and enhances our ability to address strategies 4, 5, 7, and 8 . More details are presented in the 'Implementation' section. Note that minimizing cost (strategy 6) was considered in every technical design decision.

Conveniently, designing a community-scale water treatment system, as opposed to household scale treatment units, allows us to consider the use of a wider array of technologies in the arsenic removal process. We assume that a trained technician instead of an untrained user would maintain the treatment system. We also assume access to electricity or, because of the size of the system, that it would be appropriate and affordable to incorporate a power source into the system design. Note that ARUBA treatment does not require electricity; however, hand-pumping enough water for an entire community would be impractical.

Given that the average Bangladeshi village has approximately 2000 people a community-scale treatment centre would have to provide around 4000 litres per day to meet the drinking water needs of the entire village. In Bangladesh during the summer 2008, we demonstrated the feasibility of such a treatment centre by the design and construction of a scaled-down water treatment centre - capable of treating 100-litre per hour. However, to tackle the technical issues listed above we first constructed and analysed a 10-litre per hour system. While ARUBA treatment has been standardized at a testing scale, several technical issues were solved to bring ARUBA treatment to a community-scale: (1) an effective way to mix ARUBA into large volumes of contaminated water, and (2) a low-cost method to remove the spent ARUBA from treated water.

\section{Mixing ARUBA into contaminated water}

In our small-scale batch testing, we have found ARUBA to be effective at removing arsenic if we mix 250 $\mathrm{ml}$ of contaminated water and an appropriate dose of ARUBA in a treatment bottle, shake vigorously for 30 seconds, and flip the bottle every 30 seconds for approximately one hour in order to keep the particles suspended. However, this method is impractical at a large-scale. Therefore, we investigated two mixing options: (1) maintaining particle suspension with aeration pumps and (2) mechanical mixing. Working at the Bangladesh University of Engineering and Technology (BUET) in the summer of 2008, we tested both methods. Forty grams of ARUBA were mixed into 20-litres of $2000 \mathrm{ppb}$ arsenic-spiked distilled water with 
two aquarium aeration pumps (Photograph 3) and a mechanical stirrer constructed from a kitchen mixer (Photograph 4).

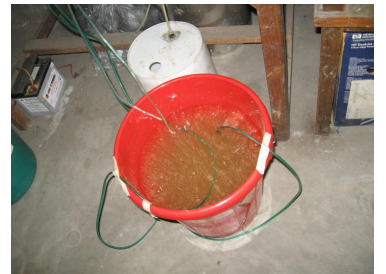

Photograph 3. ARUBA particle suspension through aeration

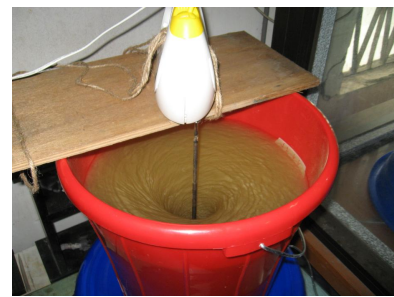

Photograph 4. ARUBA particle suspension with a mechanical mixer

The aeration pumps were found to be ineffective at maintaining ARUBA particle suspension. It was suspected that stronger, more expensive pumps would be needed to ensure particle suspension at required ARUBA concentrations. After one hour of treatment and filtration (using Whatman Grade No 1 Qualitative Filter Paper), the arsenic concentration was reduced from $2000 \mathrm{ppb}$ to $250 \mathrm{ppb}$ (as measured by arsenic field testing kit ‘Arsenic Quick' produced by Industrial Test Systems, SC, USA). An additional hour of treatment did not reduce the final arsenic concentration significantly. Although Arsenic Quick only provides approximate results, $250 \mathrm{ppb}$ is far enough from the goal of $50 \mathrm{ppb}$ to warrant rejection of this approach.

Treatment using the mechanical mixer was found to be as effective as treatment at the $250 \mathrm{ml}$ scale, reducing the arsenic concentration from $2200 \mathrm{ppb}$ to $57 \mathrm{ppb}$ (as measured by Atomic Adsorption Spectroscopy for arsenic at BUET). Therefore, we chose to incorporate a mechanical mixer into our 100litre per hour prototype design.

\section{Removal of spent ARUBA}

In our preliminary experiments in Berkeley, we used filter paper to remove ARUBA from treated water. Unfortunately, filtration membranes capable of filtering 1 to $10 \mu \mathrm{m}$ particles are very expensive for largescale water treatment. Therefore, we explored the use of a commercially available pool sand filter driven by a $1.5 \mathrm{hp}$ pump to remove ARUBA particles. We tested two filtration media: Grade \#20 silica sand (450 $550 \mu \mathrm{m})$ and ZeoSand, a natural zeolite marketed as a pool filter media that claims to have 100 times the surface area of pool filter sand.

Both filtration media proved ineffective at removing ARUBA from the treated water, even when the ARUBA-laden water was re-circulated through the filter several times. Switching to a finer media would not only be more expensive but would lead to greater filter back-pressures, necessitating a stronger, more expensive pump and/or resulting in lower flow-rates. In addition, preliminary experiments in Berkeley to determine if a coagulant could be used in order to increase particle sizes before filtration were unsuccessful. Though alum (potassium aluminium sulphate) successfully coagulated ARUBA, it was found to interfere with ARUBA's ability to remove arsenic. Polyacrylamide was inconsistent in its ability to coagulate ARUBA, though it did not interfere with arsenic removal.

In Bangladesh, we explored the use of a conical up-flow clarifier to remove ARUBA from treated water. Water enters an up-flow clarifier from the bottom of the cone and flows upward, eventually spilling over the top edge, or through an outlet pipe. Placing the bottom of the water tank that feeds the clarifier higher than the top of the clarifier ensures that the system can be gravity-fed. Due to laminar flow, particles settle to the bottom of the clarifier and can be removed through a sludge outlet pipe. Through experiments, ARUBA's settling rate was approximated to be $0.13 \mathrm{~mm} / \mathrm{s}$. Using this together with the clarifier design rule that the particle settling rate must be greater than the flow-rate divided by the cross-sectional area, we designed and built a clarifier capable of processing 10-litres per hour (Photograph 5).

Bangladesh groundwater requires higher concentrations of ARUBA than arsenic-spiked distilled water as was used in the mixing experiment detailed above (Gadgil et al. 2008; Mathieu et al. 2008). Therefore, we treated 20-litres of Bangladesh groundwater at an arsenic concentration of $800 \mathrm{ppb}$ (as measured by Inductively Coupled Plasma - Mass Spectrometry for arsenic) with $80 \mathrm{~g}$ of ARUBA and compared final arsenic concentrations in water that had been (1) filtered through Whatman Grade No 1 Qualitative Filter 


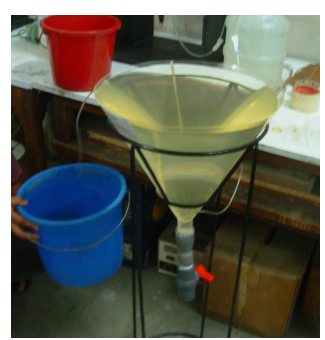

Photograph 5. $10 \mathrm{~L} / \mathrm{h}$ prototype clarifier being tested at BUET in Summer 2008

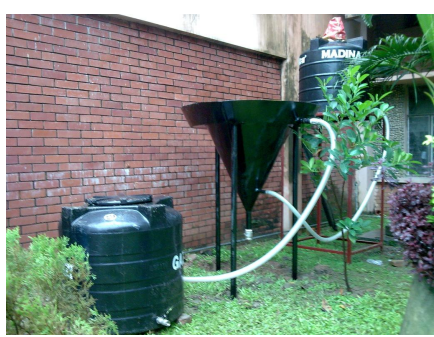

Photograph 6. $100 \mathrm{~L} / \mathrm{h}$ prototype system temporarily installed at BUET for testing

Paper, (2) passed through the clarifier, and (3) skimmed from the top of a bucket where ARUBA had been left to settle for 3 days. Results, as shown in Figure 1, indicate that water passing through the clarifier carries with it a small quantity of ARUBA and/or naturally occurring precipitated iron, to which arsenic is bound. This is likely due to variable flow-rates resulting from the use of an imprecise flow control valve (and possibly an underestimation of ARUBA's settling rate).

In order to improve the clarifier's performance we again sought a coagulant. A polyelectrolyte commonly used in local water treatment systems was purchased in Dhaka for Tk 400 (approximately US\$6, assuming an exchange rate of Tk 68 to US\$1) per kg. Experiments showed that a small amount of the polyelectrolyte $(0.003 \mathrm{~g}$ in $250 \mathrm{ml})$ was effective at coagulating ARUBA and did not interfere with arsenic removal. Therefore, this polyelectrolyte could be incorporated into the treatment process without adding significant cost.

In two separate tests, we treated 20-litres of Bangladesh groundwater at initial arsenic concentrations of $570 \mathrm{ppb}$ and $590 \mathrm{ppb}$ (as measured by ICP-MS for arsenic) with $80 \mathrm{~g}$ of ARUBA and compared final arsenic concentrations in water that had been (1) filtered and (2) treated with the polyelectrolyte and passed through the clarifier. The results in Figure 2 show that both methods produced similar results. It is possible that this coagulant could also be used in conjunction with the sand filter; however, this has not yet been attempted.
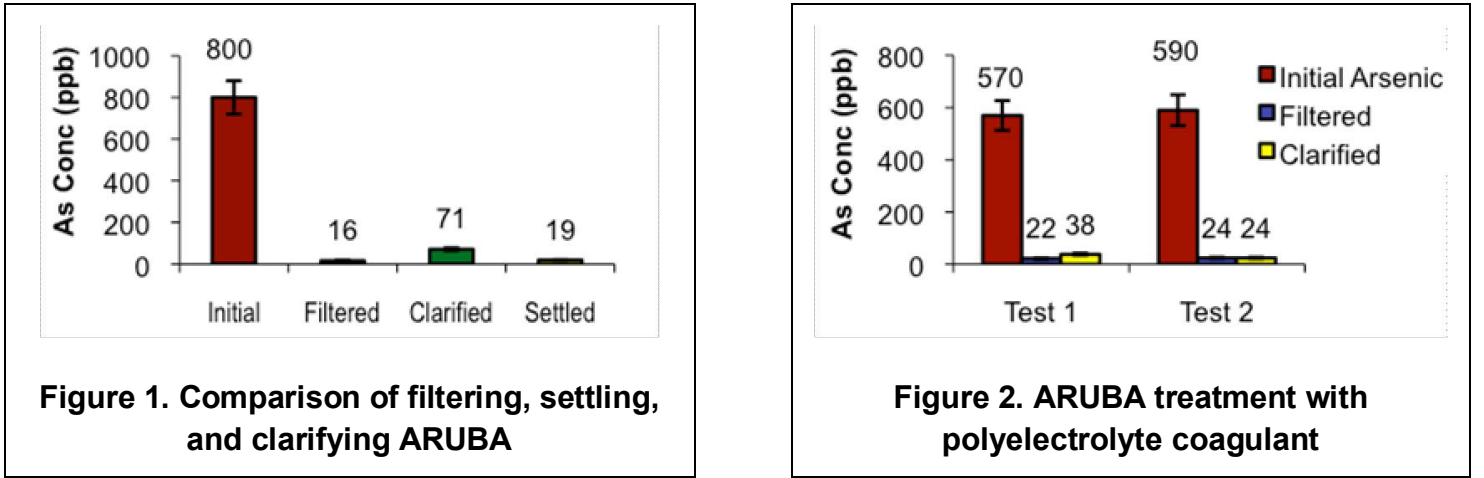

\section{0-Litre per hour prototype design}

Based on the results presented above we have designed and constructed a 100-litre per hour prototype water treatment system that uses ARUBA to remove arsenic from contaminated groundwater (Photograph 6). Water is pumped into a 500-litre tank where ARUBA is added and mixed for one hour with a propeller attached to a small motor. Polyelectrolyte is added and mixed for 15 minutes. The valve connecting the tank to a large custom-made clarifier is opened, and due to gravity and manual valve adjustments the water passes through the clarifier. Clean water is stored in a 500-litre holding tank. The system is currently undergoing preliminary testing at BUET before field-testing in two Bangladeshi villages. Ideas for future design improvements include adding a pre-treatment storage tank so that pumping water and mixing ARUBA could occur simultaneously, and adding a post-clarification filter that could remove any final traces of ARUBA. Importantly, this filter would not need frequent maintenance since the clarifier precedes it.

\section{Cost analysis}


The cost of raw materials needed for ARUBA production is expected to be low - less than half of one US cent per kg. ARUBA handling, transport, storage, delivery, and margins for distribution and retailing are expected to be on the order of US\$0.10 per $\mathrm{kg}$ (based on the assumption that these costs would be comparable to those associated with ground, iodized table salt in India). Costs associated with the centralized ARUBA manufacturing are still a subject of research but are expected to be low due to the simple processes involved.

Generously assuming that the manufactured cost would be double the raw material cost (US\$0.20 per $\mathrm{kg}$ ), the cost of treating $400 \mathrm{ppb}$ arsenic water for one household (five people) for one year, assuming each person consumes two litres of drinking water per day, is estimated to be only US $\$ 3$, less than that of household arsenic removal filters on the market (US\$40-\$50 for a filter rated for 5 years). Note that our cost estimate does not include the capital cost of the treatment centre, as that would be heavily dependant on the implementation plan and financing. It also does not include the cost of waste disposal.

For neighbouring West Bengal, India, the welfare benefit of eliminating exposure to arsenic in drinking water (at a concentration of $400 \mathrm{ppb}$ ) is estimated to be approximately US\$48 per household per year (calculation based on that of Roy 2008). We expect this figure to be similar in Bangladesh, indicating that the cost of arsenic removal is less than the benefits attributed to drinking clean water. Moreover, according to Ahmad et al. (2003) the mean willingness to pay for recurring costs associated with an arsenic-free standpost is approximately US\$9 per year. As the estimated cost of using ARUBA to provide arsenic-free drinking water is less (US\$3 per year), ARUBA promises to be affordable and economically sustainable.

\section{Implementation}

One possible implementation model is a public-private partnership similar to that developed by WaterHealth International (www.waterhealth.com), which provides clean drinking water to more than a million people in rural India through publicly owned, privately managed village-scale water treatment centres. Through a three-way partnership between a local financial institution, a local NGO, and a company responsible for constructing and maintaining the water treatment centres (all working together with the local village governments), community-scale water treatment plants could be constructed in rural Bangladeshi villages. The water would not only be treated for arsenic, but also pathogens and other chemical contaminants, enhancing the perception of treated water quality (strategy 4). Users would pay a small fee for the safe drinking water that they collect from the treatment centre, but due to the low-cost of ARUBA the fee would remain affordable to those living on less than US\$2 a day (strategy 6) and would be enough to cover both the capital and operating costs of the treatment centre.

This implementation plan meets the design strategies listed above. In addition to being effective and lowcost, community-scale treatment using ARUBA leads to ease in water quality monitoring (strategy 5), local water management (strategy 7), and waste management (strategy 8). Villagers would not be required to maintain their own water treatment system, meaning that the system would be convenient to users. However, water delivery (strategy 3 ) would be essential for the success of the water treatment system. We believe this feature could be built in at a low-cost.

\section{Conclusions and learning points}

Considering both technical scalability and sustainability early on is essential for the success of technologyrelated projects in the developing world. We have presented the design and analysis of a low-cost, community-scale water treatment plant that uses ARUBA to remove arsenic from contaminated groundwater in Bangladesh, and a possible implementation plan. Examination of relevant multidisciplinary studies, along with observations and informal interviews leads to development of design strategies that ensure technologies and implementation plans will be acceptable to users. In rural communities, costs and perceived convenience are key in increasing technology adoption rates. Implementation of ARUBA through a public-private partnership can address both of these issues.

\section{Acknowledgements}

We would like to thank our funders: NCIIA and UC Berkeley's Blum Center, Bears Breaking Boundaries Contest, and the Sustainable Products and Solutions Program. We would also like to thank LBNL, BUET, and BRAC. Thanks to the many people who contributed to this project: Susan Amrose, William Babbitt, Yola Bayram, Ebere Chukwueke, Raymond Dod, Meghana Gadgil, Christie Galitsky, Lara Gundel, Kosar Jahani, Tasnuva Khan, Mathew Jeung, Nadia Madden, Melissa Quemada, Heena Patel, Clete Reader, 
Mehmet Seflek, Mark Sippola, and Duo Wang. Iqbal and Kamal Quadir provided us funds and support for our first trip to Bangladesh and the Khan family greatly supported our second trip. Finally, thanks to our Bangladeshi collaborators Dr. A.B.M. Badruzzaman and Mahbuba Iasmin Ahmed at BUET for their support during our third visit to Bangladesh.

\section{References}

Ahmad, J., B.N. Goldar, S. Misra, and M. Jakariya (2003) "Willingness to Pay for Arsenic-Free, Safe Drinking Water in Bangladesh.” World Bank Water and Sanitation Program- South Asia.

Biswas, B.K., R.K. Dhar, G. Samanta, B.K. Mandal, D. Chakraborti, I. Faruk, K.S. Islam, M. Chowdhury, A. Islam, and S. Roy (1998) "Detailed study report of Samta, one of the arsenic-affected villages of Jessore District, Bangladesh.” Current Science. Vol 74, No 2, p 134-145.

Caldwell, B.K., J.C. Caldwell, S.N. Mittra, and W. Smith, 2003 "Searching for an optimum solution to the Bangladesh arsenic crisis." Social Science \& Medicine. Vol 56, p 2089-2096.

Chen Y. and Ahsan H (2004). "Cancer burden from arsenic in drinking water in Bangladesh." American Journal of Public Health. Vol 94, No 5, p 741-744.

Chowdhury, A.M.R. (2004) “Arsenic Crisis in Bangladesh.” Scientific American: Aug 2004. p 87-91.

Gadgil, A.J., L.A. Gundel, and C. Galitsky (2008). "Arsenic remediation of Bangladesh drinking water using iron-oxide coated coal ash," in Arsenic Contamination of Groundwater: Mechanism, Analysis, and Remediation. Ahuja, S. (ed.) John Wiley and Sons. (in press)

Hoque, B.A., M.M. Hoque, T. Ahmed, S. Islam, A.K. Azad, N. Ali, M. Hossain, and M.S. Hossain (2004) "Demand-based water options for arsenic mitigation: an experience from rural Bangladesh." Public Health. Vol 118, p 70-77.

Hoque, B.A., A.A. Mahmood, M. Quadiruzzaman, F. Khan, S.A. Ahmed, S.A.K.A.M. Shafique, M. Rahman, G. Morshed, T. Chowdhury, M.M. Rahman, F.H. Khan, M. Shahjahan, M. Begum, and M.M. Hoque (2000) "Recommendations for water supply in arsenic mitigation: a case study from Bangladesh.” Public Health. Vol 114, No 6, p 488-494.

Hussam, A. and A.K.M. Munir (2007) "A simple and effective arsenic filter based on composite iron matrix." Journal of Environmental Science and Health Part A. Vol 42, p 1869-1878.

Mathieu, J.L., A.J. Gadgil, K. Kowolik, and S.E. Amrose (2008) "Removing arsenic from contaminated drinking water in rural Bangladesh: Recent fieldwork and policy implications.” Proceedings of UNC Environmental Symposium: Safe Drinking Water, 5-6 Nov 2008.

Patel, H. A.J. Gadgil, C. Galitsky, E. Chukwueke, D. Wang, M.R. Sippola, A.L. Blumstein, Y. Pang, L.A. Gundel (2006) "A low cost method for removing arsenic from drinking water: Coal ash coated with ferric hydroxide." Proceedings of UNC Environmental Symposium: Safe Drinking Water, 16-17 March 2006.

Roy, J. (2008) "Economic benefits of arsenic removal from groundwater- A case study from West Bengal, India." Science of the Total Environment. Vol 397, p 1-12.

Smith, A.H., E. O. Lingas, and M. Rahman, (2000) "Contamination of drinking-water by arsenic in Bangladesh: A Public Health Emergency.” Bulletin of the World Health Organization. Vol 78, No 9, p 1093-1103.

\section{Keywords}

arsenic removal, Bangladesh, bottom ash, user-centred design

\section{Contact details}

Johanna L. Mathieu

Department of Mechanical Engineering

University of California, Berkeley

6102 Etcheverry Hall Mail Code 1740

Berkeley, CA 94720 USA

Tel: +1 (207) 240-8428

Email: jmathieu@berkeley.edu

www: http://arsenic.lbl.gov

\author{
Dr. Ashok J. Gadgil \\ Lawrence Berkeley National Laboratory \\ 1 Cyclotron Rd MS 90R3058 \\ Berkeley, CA 94270 USA \\ Tel: +1 (510) 486-4651 \\ Fax: +1 (510) 486-6658 \\ Email: ajgadgil@lbl.gov \\ www: http://eetd.lbl.gov/staff/gadgil/AGadgil.html
}

